\title{
INFLUENCE OF STATOR EMBRACE ON TORQUE OF IN-WHEEL SWITCHED RELUCTANCE MOTOR
}

\author{
Merve YILDIRIM ${ }^{* 1}$, Hasan KURUM ${ }^{2}$ \\ ${ }^{1,2}$ Department of Electrical and Electronics Engineering, University of Firat, Elazı $\breve{g}$, Turkey \\ *merveyildirim@firat.edu.tr
}

\begin{abstract}
In this paper, influence of stator pole embrace on torque of In-Wheel Switched Reluctance Motor (IW-SRM) is investigated by numerical modeling based on Finite Element Method (FEM). For this reason, 3D numerical model of IWSRM is built by using Ansys Maxwell Software Package. IW-SRM is analyzed and output torque and magnetic flux density of the IW-SRM are calculated. The analysis of IW-SRM is realized for different stator pole embraces and the results of the output torque and magnetic flux density of IW-SRM taken for various stator pole embraces are compared with each other. As seen from the results, when the value of stator pole embrace reduces, the output torque of IW-SRM increases. As a result in this study, the effects of different stator pole embraces are examined on the output torque of IW-SRM.

Key words: In-Wheel Switched Reluctance Motor, Torque, Ansys Maxwell, Finite Element Method
\end{abstract}

\section{Introduction}

Switched Reluctance Motors (SRM) are simple machines due to important advantages such as high reliability, low maintenance requirement, good performance, low cost and weight, and robust construction [1]. Rotor can reach very high speeds and there are not rotor copper losses because of not having permanent magnets and windings in the rotor. Therefore, they are commonly used in automotive, wind energy, aerospace and home applications [2, 3, 4]. SRMs use reluctance torque originated in magnetic saliency between stator and rotor poles. On the contrary, SRMs have some drawbacks such as vibration, torque ripple, and acoustic noise. Torque ripple can obtain smaller by the control [5].

In SRM design, pole embrace is an important issue for good performance of SRM. Embrace coefficient affects the rotor and stator tooth width. Furthermore, the pole embrace changes the average torque and torque ripple [6]. Therefore, it should be properly selected in design of SRM.

There are some studies on the effect of the SRM geometry to the SRM performance in the literature. In [6], the influence of pole embrace on SRM design is explained. By changing the stator and rotor pole embrace from 0.2 to 0.5, FEM analysis is carried out by Ansys Package Software. The pole embrace value provided the highest average torque and lowest torque ripple is selected.

In [7], the effects of windows in stator and rotor poles of SRMs for decreasing the noise and vibration which are the most disadvantages for SRMs are investigated. An electromagnetic analysis based on FEM is realized to optimize the window for stator and rotor. It is observed that the windowed stator and rotor of SRM have quite similar influence on the vibration and acoustic noise reduction. [8] explains the skewing effects on the vibration reduction of three phase SRMs with 12/8-pole. A skewed rotor-SRM, a skewed stator-SRM, and a skewed stator and rotor-SRM are handled. The analyses are 
realized for different skewing angles by the FEM and tested experimentally on the four motors. The inductance and torque characteristics of the four motors are also compared with each other. The effects of magnetic circuit geometry on torque generation of $8 / 14$ SRM is presented in [9]. The motor is analyzed by 2D FEM. It is seen that the rotor diameter and the width of the stator and rotor poles have the biggest effect on the developed torque because of the higher number of rotor poles to the stator poles. Authors in [10] study on the effects of magnetic circuit geometry on characteristics of SRMs. The static and steady state characteristics such as flux linkage, speed, current and torque of the SRM are examined for four magnetic structures which are 8/6, 16/12, 16/14, and 16/18 by FEM analysis. The static characteristics are calculated for various rotor positions and excitation currents by using FEM analysis. Dynamic characteristics are also calculated by developed software at Matlab/Simulink. According to the analyses, it is obtained that as the number of poles increases the core losses also increase.

In this study unlike conventional SRMs, IW-SRM whose rotor is out of the motor is studied. Effect of stator embrace on torque of IW-SRM is examined by FEM. The analysis of IW-SRM is realized as 3D by using Ansys Maxwell for different stator embraces. The results of magnetic flux density and output torque are obtained for these stator embraces.

In the paper, the geometry of IW-SRM is explained in Section 2. Section 3 defines the pole embrace. In Section 4, Ansys Maxwell 3D analysis results of IW-SRM are given for different stator embraces. Conclusions are explained in the last section.

\section{In-wheel switched reluctance motor geometry}

IW-SRMs have outer rotor structures and their stators are in the motor. In this study, 18/12 IWSRM unlike conventional SRM is modelled by Ansys Maxwell 3D Software Package based on FEM. The geometry of IW-SRM is shown in Fig. 1.

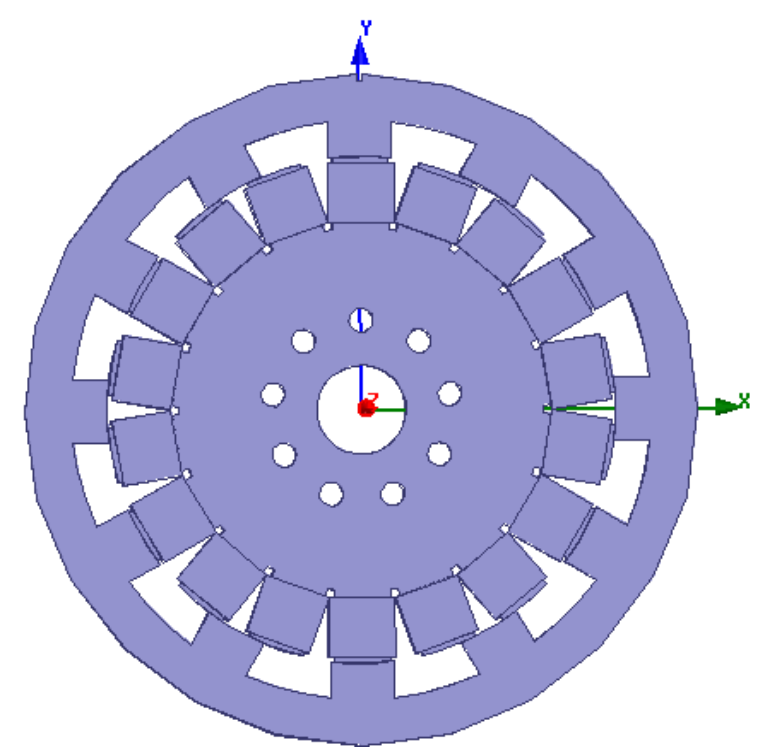

Figure 1. IW-SRM geometry

The motor design parameters are given in Tab. 1. 
Table 1. Motor design parameters

\begin{tabular}{|c|c|c|}
\hline $\mathrm{N}_{\mathrm{r}}$ & The number of rotor poles & 12 \\
\hline $\mathrm{N}_{\mathrm{s}}$ & The number of stator poles & 18 \\
\hline $\mathrm{R}_{\mathrm{sh}}$ & Diameter of the shaft & $60 \mathrm{~mm}$ \\
\hline $\mathrm{D}_{0}$ & Outer diameter of the motor & $450 \mathrm{~mm}$ \\
\hline $\mathrm{D}$ & Inner diameter of the motor & $372.8 \mathrm{~mm}$ \\
\hline $\mathrm{W}_{\mathrm{g}}$ & Width of airgap & $0.5 \mathrm{~mm}$ \\
\hline $\mathrm{L}$ & Package size & $100 \mathrm{~mm}$ \\
\hline $\mathrm{C}_{\mathrm{in}}$ & Inner iron thickness & $83 \mathrm{~mm}$ \\
\hline $\mathrm{C}$ & Outer iron thickness & $31 \mathrm{~mm}$ \\
\hline
\end{tabular}

The voltage of IW-SRM can be defined as follows [11]

$$
V=I \cdot R+\frac{d \varphi(\theta, i)}{d t}=I \cdot R+L(\theta, i) \frac{d i}{d t}+I \cdot \omega \frac{d(L(\theta, i)}{d \theta}
$$

where $\varphi$ is the flux linkage, $L$ is the inductance, $\omega$ is the rotating speed of the motor, $I$ is the current.

The magnetic co-energy of the motor can be given as

$$
W_{e}=\int \varphi d i
$$

The electromagnetic torque can be calculated by

$$
T_{e}=\frac{d w_{e}}{d \theta}
$$

The torque equation can be simplified as follows

$$
T_{e}=\frac{1}{2} \cdot \frac{d L}{d t} \cdot I^{2}
$$

\section{Explanation of pole embrace}

Pole embrace is defined as the ratio of pole arc to pole pitch which can be expressed as follows

$$
\text { Embrace }=x / y
$$

where $x$ and $y$ are pole arc and pole pitch of the SRM, respectively. The pole embrace is shown in Fig. 2. 


\section{Figure 2. The illustration of the pole embrace [6].}

The selection of pole embrace is quite important for the performance of IW-SRM. Embrace coefficient of IW-SRM affects to the rotor and stator tooth widths. The change of the pole embrace also influences to the average of the torque and torque ripple. Therefore, the pole embrace should be selected to meet the motor condition regarding on the starting capability, the minimum inductance value during the misaligned condition of the diametrical poles, and while minimizing the switching frequency of phase winding [6].

In this study, the pole embrace is changed for examining the effect to the torque of IW-SRM. Three values of pole embraces which are 0.6, 0.55, and 0.5 are used as shown in Fig. 3.

a.

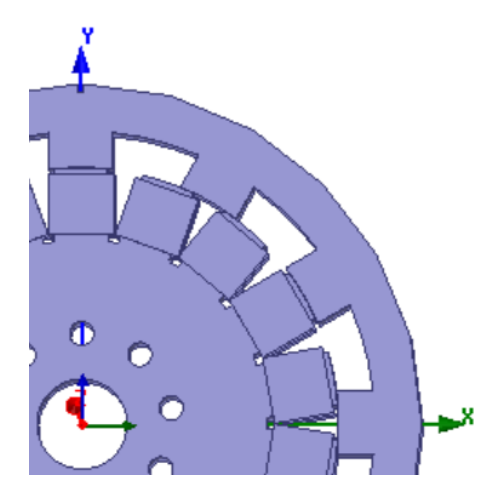

b.

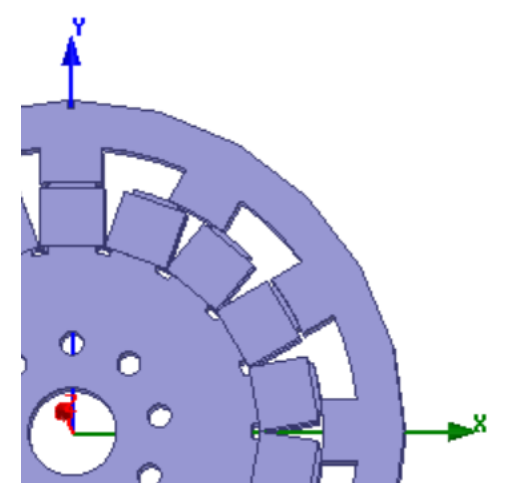

c.

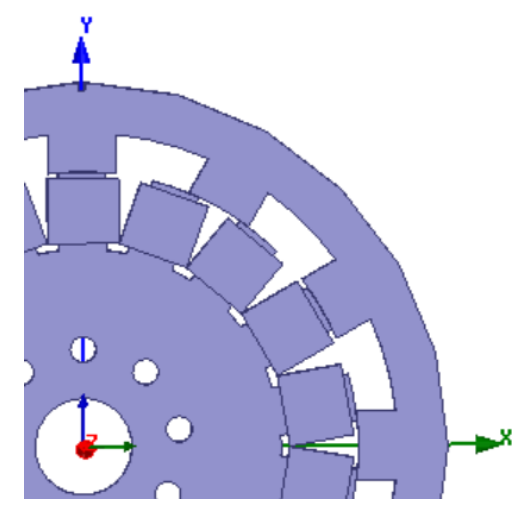

Figure 3. The IW-SRM geometries for different stator pole embraces investigated in this study: a. the pole embrace $0.6, \mathrm{~b}$. the pole embrace 0.55 , and c. the pole embrace 0.5 . 


\section{Results and discussions}

In this section, the results for different stator pole embraces of IW-SRM motor are explained. Firstly, 3D numerical model of IW-SRM is built by using Maxwell Software Package. Then, the IWSRM is analyzed for different stator pole embraces which are $0.6,0.55$, and 0.5 . Torque results of IWSRM are compared for these stator pole embraces in Fig. 4.

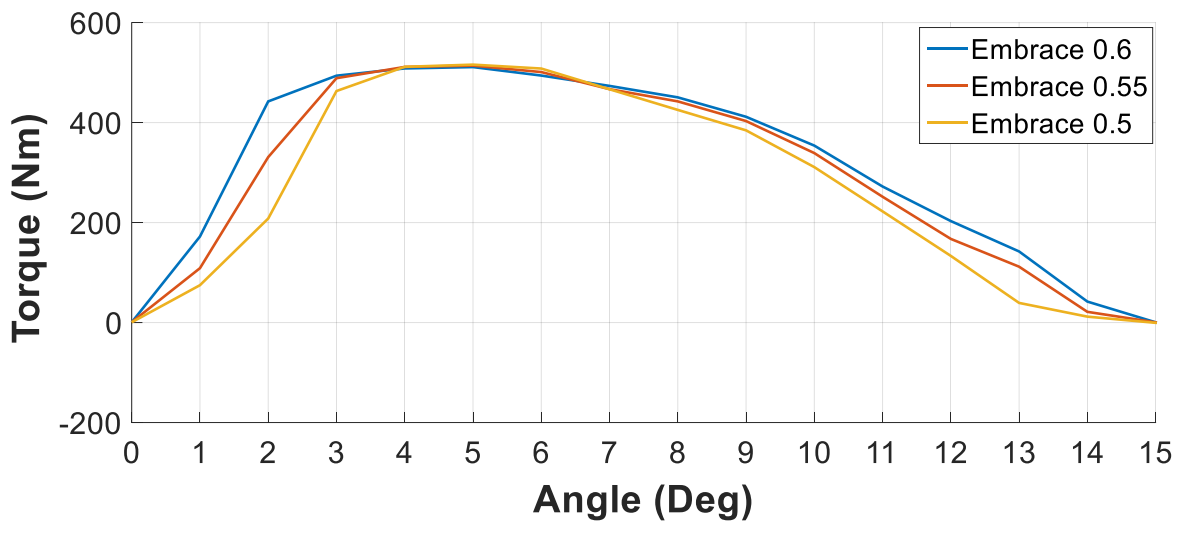

Figure 4. Torque curves of IW-SRM for different stator pole embraces

As seen in the Fig. 4, when the value of stator pole embrace decreases, the output torque of IW SRM rises. The distributions of the magnetic flux density B [T] for these stator pole embraces are illustrated in Fig. 5.

a.

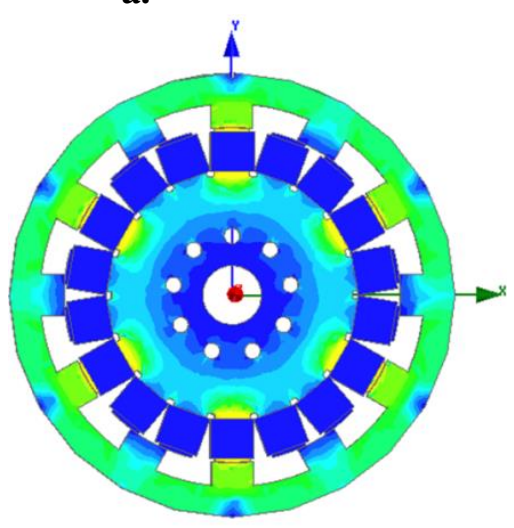

b.

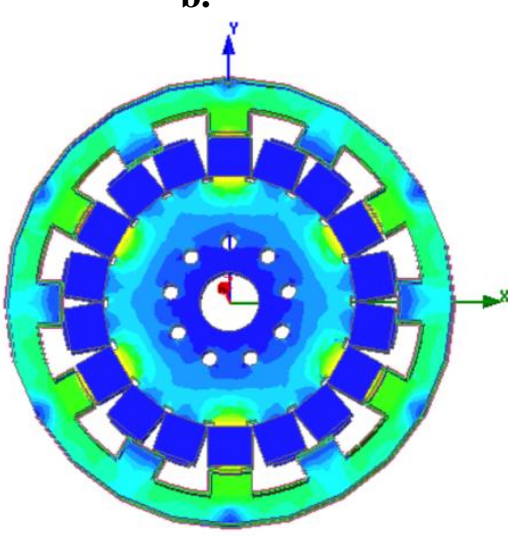

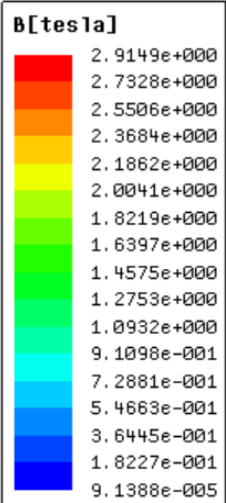

c.
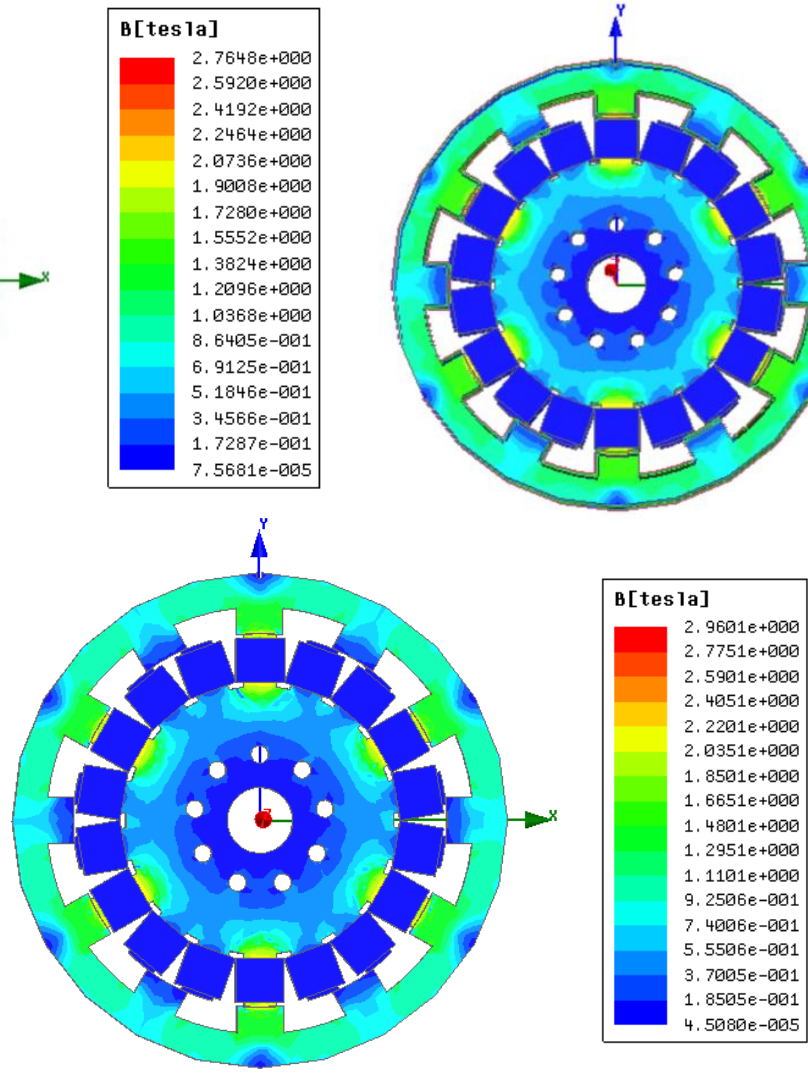

Figure 5. Magnetic flux density for stator pole embrace $0.6 \mathrm{~b}$. Stator pole embrace $0.55 \mathrm{c}$. Stator pole embrace 0.5 
Fig. 5 shows that the highest value of the magnetic flux density $\mathrm{B}$ is for the lowest stator pole embrace 0.5 . As the value of the stator pole embrace rises, B decreases.

\section{Conclusions}

In this study, the effect of stator pole embraces on the torque of the IW-SRM is examined by using Ansys Maxwell Software. IW-SRM is firstly modeled as 3D and the magnetic flux density distribution and the torque of IW-SRM are also successfully calculated and analyzed. The results show that the torque strongly depends on the stator pole embrace. The highest torque is obtained with the lowest stator pole embrace 0.5 , while the lowest torque is obtained with the highest stator pole embrace 0.6. The increasing of stator pole embrace means less torque ripple and width variation of torque profile. According to the simulation results, the stator pole embrace must be selected as 0.5 to obtain high output torque. The magnetic flux density for the analysis used higher stator pole embrace is also lower. As seen in the results, as the stator pole embrace decreases, the output torque and the magnetic flux density of IW-SRM increase. Therefore, proper stator pole embrace should be selected for optimum design of IWSRM for highest torque and magnetic flux distrubution.

\section{References}

[1] Yildirim, M., Polat, M., and Kürüm, H., A survey on comparison of electric motor types and drives used for electric vehicles, IEEE 16th International Power Electronics and Motion Control Conference and Exposition (PEMC), Antalya, Turkey, 2014, pp. 218-223.

[2] Urbanski, K., and Krzysztof, Z., Sensorless control of SRM using position observer, IEEE European Conference on Power Electronics and Applications, 2007, pp. 1-6.

[3] Omaç, Z., Polat, M., Öksüztepe, E., Yıldırım, M., Yakut, O., Eren, H., and Kürüm, H., Design, analysis, and control of in-wheel switched reluctance motor for electric vehicles, Electrical Engineering, (2017), pp. 1-12.

[4] Chiang, C., Hsieh, M. F., Li, Y. H., and Tsai, M. C., Impact of electrical steel punching process on the performance of switched reluctance motors, IEEE Transactions on Magnetics, 51 (2015), 11, pp. 1-4.

[5] Goto, H., Murakami, S., and Ichinokura, O., Design to maximize torque-volume density of axialflux SRM for in-wheel EV, IEEE 41st Annual Conference of the Industrial Electronics Society (IECON), 2015, pp. 005191-005196.

[6] Karim, K. A., Abdullah, N., Nazri, M., Othman, S. A. T., Firdaus, R. N., and Zainal, N. Z., Effect of poles embrace on switched reluctance motor design, Journal of Multidisciplinary Engineering Science Studies (JMESS), 3 (2017), 4, pp. 1661-1664.

[7] Elamin, M., Yasa, Y., Sozer, Y., Kutz, J., Tylenda, J., \& Wright, R. L. (2017, May). Effects of windows in stator and rotor poles of switched reluctance motors in reducing noise and vibration. In Electric Machines and Drives Conference (IEMDC), 2017 IEEE International (pp. 1-6). IEEE. 
[8] Gan, C., Wu, J., Shen, M., Yang, S., Hu, Y., \& Cao, W. (2015). Investigation of skewing effects on the vibration reduction of three-phase switched reluctance motors. IEEE Transactions on Magnetics, 51(9), 1-9.

[9] Smaka, S., Cosovic, M., \& Masic, S. (2013, October). The effects of magnetic circuit geometry on torque generation of 8/14 switched reluctance machine. In Information, Communication and Automation Technologies (ICAT), 2013 XXIV International Symposium on (pp. 1-6). IEEE.

[10] MašiĆ, Š., Smaka, S., Salihbegović, I., \& Ćosović, M. (2011, May). The effects of magnetic circuit geometry on characteristics of switched reluctance motors. In Electric Machines \& Drives Conference (IEMDC), 2011 IEEE International (pp. 1427-1432). IEEE.

[11] Zhu, J., Cheng, K. W. E., and Xue, X., Torque analysis for in-wheel switched reluctance motors with varied number of rotor poles, IEEE International Symposium on Electrical Engineering (ISEE), 2016, pp. 1-5. 